\title{
Commonplace
}

\section{Navigating the Information Landscape: A Media Literacy Toolkit Series}

\section{Whitney Phillips}

Published on: Jun 30, 2020

DOI: $10.21428 / 6 \mathrm{ffd} 8432.37155 \mathrm{cc} 8$

License: Creative Commons Attribution 4.0 International License (CC-BY 4.0). 
When you venture into the forest, you need to bring supplies. The further out you go, the more important those supplies become. To figure out what you need to bring, it's common sense-indeed, it's a basic survival strategy - to consider where you're heading, what you'll be doing, and how long you'll be gone.

The same holds online. To avoid falling down algorithmic rabbit holes, to avoid falling for the latest media manipulation campaign, and more broadly, to avoid falling flat on our faces, we need tools for navigation, verification, and analysis.

There are limits to this parallel. As Anthony Nadler emphasizes, the problem with likening online environments to offline environments is that online environments are made by people-and, very often, particular kinds of people-within existing political, economic, and social structures. Any claim that positions digital media as somehow "natural" risks normalizing encoded inequalities and biases (for more on what lurks in our code, see work by Ruha Benjamin, Safiya Noble, and Cathy O'Neil). Further, it suggests that these spaces and tools couldn't be otherwise. A redwood forest couldn't be otherwise. A digital forest could be (and almost was).

The constructedness of digital environments doesn't make them less treacherous. Our networks were built to maximize social sharing. Our networks were built to maximize profits. Our networks were built to maximize what Lam Vo calls the tyranny of the loudest. The result is that information disorder, the term coined by Claire Wardle and Hossein Derakhshan, is a feature of the digital forest, not a bug. And that's why we need to come prepared.

The stakes of knowing what you're looking at online and what you should do about it have always been high; consider the history of disinformation wielded against Black feminists. 2020-a year that has become shorthand for chaos, loss, and trauma - has raised those stakes even higher. The infodemic continues to rage alongside the pandemic. Mis- and disinformation about the anti-racism protests continues to surge. The US presidential election creeps ever closer.

In the face of these compounding threats, so many people are trying to get it right. The problem is that our affordances, our attention economy, our algorithms - and all the ways these feed into and are fed by extreme, often asymmetric polarization-make it very difficult to know what "right" even looks like. The result is that we're exposed to all kinds of polluted elements, and very often, don't have the best tools for the job, if we have any tools to work with at all. Having the wrong tools can be worse than no tools at all; a backpack full of hammers might feel preferable to a backpack full of nothing, but in the middle of the forest, hammers take up space, weigh us down, and create a false sense of preparedness. Before we find ourselves too deep in the forest, we need to stop, assess what's in our bags, and see what else we might need. 
Tools like fact checking, source verification, and critical thinking-which for many people are synonymous with the very concept of "media literacy" - might seem like obvious additions to our survival kits. Who doesn't want facts, good information, or thoughtful analysis? The problem is, these tools are not failsafes. They can certainly be helpful in some cases, with some travelers, in some necks of the woods. In other cases, they can backfire. Maybe not as badly as a backpack full of hammers, but enough to keep us lost and disoriented in the forest.

As Ryan Milner and I discuss, these kinds of good-sense media literacy tools can fail, or at least can come up short, for a few different reasons. The most basic is the challenge posed by digital affordances, simply described as what technologies allow us to do with them. These affordances send content zooming, decontextualized, across and between audiences-immediately complicating what you're even looking at online, and in the process, complicating efforts to respond appropriately. (How can you fact check something when you don't know what needs to be fact checked to begin with?)

Beyond that, go-to media literacy strategies like fact checking and critical thinking tend to approach false and misleading information as singular, self-contained texts-texts that singular, self-contained internet users need to respond to as good, logical, liberal subjects. This is achieved when people do their homework. This is achieved when people determine what's true, and therefore, what's safe to share. This is achieved when people lift themselves up by their informational bootstraps.

But we don't exist atomistically, we exist ecologically, especially online, where our network connections are as dense and robust as redwood root systems. In the digital forest, there is no singular, self-contained anything. There is, instead, interconnection, reciprocity, and the fundamental overlap between this (text, platform, audience, publication) from that (text, platform, audience, publication). It's not just that we need a new set of media literacy tools to navigate this landscape. We need to see the landscape in new ways: to look $\underline{u}$ at the overlapping energies powering information storms forward, around at the ways everyday action influences our networks, and down at the systems and structures that facilitate pollution's spread.

The goal is a perspective that's both birds-eye and zoomed in. This tension is epitomized by Jeffrey A. Tolbert and Bryan Rupert's exploration of local cosmologies. The "local" in local cosmologies refers to everyday, immediate, subjective experiences. Peppering that landscape is what Milner and I call deep memetic frames, ways of being and seeing that direct someone's attention to some things but not others; prime them to respond to information in certain ways; and maintain divisions between the us the person identifies with and the them the person others. A person's cosmology-their broad conception of what the world is like and how they fit within it-emerges from the spot where that person is standing, and which deep memetic frames they're standing behind. 
Local cosmologies and their constitutive frames are deeply personal. But they don't emerge in a vacuum. They are, instead, a function of other, much vaster, structures; all the geopolitical, economic, and historical preconditions within the environment that make even the most idiosyncratic local cosmologies possible, even inevitable. At least, that set up certain people, with certain standpoints, to experience the world in certain ways-for better and for much, much worse, depending on how much is revealed, and how much is obscured, as a result.

To understand the landscape we're traveling, the challenges we'll face, and what we need to pack, we must zoom out to account for the complex connections between local cosmologies, deep memetic frames, and all the structuring preconditions that furnish the ideological and material resources for both - a process that also means accounting for the often vast discrepancies between the assertion "this is what the world is like," and what is actually in the world.

Doing so pushes the boundaries of "media literacy" well beyond media, and indeed, well beyond literacy - at least media and literacy in any traditional sense. Thinking ecologically means we don't need to draw lines between anything. It all counts; it's all relevant to our journey through the forest.

That is the ethos of this toolkit. It will, of course, include practical submissions: better practices for responding to harmful content, tips for assessing the truth-value of information (never forgetting that true information can be just as polluting as false information), and other specific, actionable, ecologically-sensitive tools necessary to hacking our way through the underbrush.

Without a bird's eye view, however, even the most precise zoom lens won't tell us very much. So in addition to everyday best practices, we must also critically reflect on why the forest looks the way it does, how it was allowed-indeed, how it was encouraged - to become so polluted, and when these particular trails were blazed, by whom, and at whose expense. Capitalism, liberalism, and institutional white supremacy, for example, are structuring preconditions for a great deal of polluted information online. Without understanding these existing systems, we can't understand how we arrived at this spot in the forest. And if we don't understand how we arrived at this spot in the forest, we won't know what path to take-or to forge-next.

Just as critically, if we have any hope of effectively navigating the forest, we need to explore what it means to be a person in that forest. Disinformation is a mental health crisis as much as it is an informational one; it's also a profound social justice issue, long emphasized by researchers like Shireen Mitchell and Mutale Nkonde. Discourses around trauma, mindfulness, and emotional intelligence; bystander intervention and de-escalation; and anti-racism and responsible allyship are as relevant to media literacy as the most straightforward fact checking guide. 
We have a hell of a journey ahead of us. We must work across disciplines, professions, and belief systems to make sure there are ample supplies for everyone. An immediate goal is ensuring our own safe passage. But by packing our own bags carefully, we'll be better prepared to help others pack theirs. The forest may still be dark; the path ahead still treacherous. But we'll be in a better position to get somewhere new-a grove that is safer and more equitable for all-if we zoom our lenses out while also zooming in.

Acknowledgments: I offer my sincerest thanks to Diane Grimes for gifting me with the image of a backpack full of hammers; Ryan Milner for the soundboarding and support, as always; and Jeffrey A. Tolbert for regrounding me in metaphors of place. 